\title{
The Non-Linear Nature of Emergent Teaching: A Multi-threaded Tale
}

\author{
SAM CROWELL \& DAVID REID-MARR \\ California State University-San Bernardino (United States)
}

\begin{abstract}
This essay offers a narrative that illustrates the non-linear nature of emergent teaching and how its outcomes are multifaceted and mutually causative. In other words, they lead us in many directions at once. This quality of non-linearity is central to the concept of emergence. Emergent teaching begins by recognizing that reality is fundamentally non-separate. By realizing we are not separate in our actions, words, and deeds we confirm a connectedness to one another and the world. This is essential to fully understand emergence. When perceived as a whole, every action in the universe is mutually dependent upon every other interaction. In this way, the universe is constantly creating itself. Emergent teaching moves us toward an awareness of the reality of cocreation. Non-separation creates the foundation of a dynamically interconnected and emergent universe.
\end{abstract}

Human activity in the world is sometimes portrayed as a pebble being thrown into a pond. The ripple of waves goes in all directions at the same time. Many of the influences may actually be unseen and unknown as our actions merge with the greater whole. I was watching it rain recently while renting a lakeside cottage. Sprinkling at first, each drop of rain created its own circular life-world as it hit the surface of the lake. As the drops of rain pierced the surface each one caused a small splash upward followed by tiny circular ripples which would soon encounter other small riplets coming its way. The entire lake took on a different effect as I looked across its surface. As the rain came down harder, I thought how sky water and lake water become indistinguishable. When the rain stopped, the heat of the day returned and I could see a soft vapor rise across the lake, filling the atmosphere with humidity and the beginning of a new cycle of 
transformation and change. A nearby stream was rushing its newly collected water into the lake as I took in the fresh exuberance left by the rain.

Just as in this example of a summer shower, emergent teaching is not a singular or linear process but seems to have lingering spheres of influence that become hard to distinguish or measure or classify. As teachers and educators, we often have very linear concerns. We are trying to help our students learn particular skills or information, or help them understand concepts that will shape their thinking and understanding. We are trained to assist in this process through a variety of techniques, to organize what comes first and second, and to assess whether or not the student has "learned" what we taught to a sufficient degree. These kinds of linear concerns become second nature to us; it is sometimes difficult to even conceive of "teaching" apart from them.

Stephen Buhner (2004) has observed, however, that "we in the West have been immersed in a particular mode of cognition that is defined by its linearity, its tendency to reductionism, and its insistence on the [mechanization] of Nature" (p. 1). This mode of cognizing our experience in the world has affected all of us, and all our institutions. Sociologists would tell us that part of us becomes bound up in the institutional structures we participate in. The structural elements of our institutions embed these mechanistic and linear ideas into day-to-day practices that dominate our lives, the expectations placed upon us, and the processes and content accepted as legitimate and authoritative. It has become a closed system of truth that is self-perpetuating. It is a system of thought that now depends on ignoring or leaving out anything that does not fit within its parameters. The consequences of continuing this way of thinking and perceiving the world can be disastrous. As educators, we not only live within these structures, we, perhaps more than any other group perpetuate many of these ways of thinking through the curriculum and content, through the organization of the school schedule, and through many of our teaching and evaluation processes.

David and I teach collaboratively in a Masters degree program in Holistic and Integrative Education. One of our courses uses art and nature to explore, among other things, the nature of process, creativity, and emergence. A few years ago, David planned an art experience for our students that introduced them to sand painting. He prepared forms that were four feet square and students, in groups of four, were asked to work in sections where they would create a sand painting that characterized some key aspects of their locality, the place where they lived. These characterizations could be from their experience, their feelings, or more obvious demarcations of history, geography or culture. In the center where the quadrants met was a circular area in which students would bring actual earth or physical artifacts that symbolized "place." David demonstrated ways students could use color, images, and symbols in the creation of the sand paintings. While each student was free to express herself creatively and independently, we asked that their independent pieces contribute to a sense of unity. The process was characterized by openness, collaboration, and the students were encouraged to bring their own experience into their projects.

One group of students lived in a mountain town that had recently been devastated by forest fires. Many people they knew had lost their homes and the entire community 
was deeply affected by the impact these fires had on virtually every aspect of life. They decided to bring ashes that represented various areas that were burned. At the end of the project, they became very emotional as they shared their sand painting and described what it symbolized for them. After taking pictures of their work, the students then poured the sand into large five gallon buckets and took them outside to an undeveloped area of the campus. We asked them to give the sand back to the earth, offering prayers of gratitude and sustenance for the communities represented. When we processed the sand painting experience, most of the comments had little to do with the art processes. Rather all the students made connections to various parts of their lives, their histories, the places where they lived. The process of dismantling their creations was difficult for them but they saw in it the temporality of life and as they returned the sand to the earth there was a sense of completion as well as a sense of participation and connection they felt with the prayers that had been offered.

After the project, the two students who lived in the mountain community ravaged by fires could not forget the impact of the sand painting experience. In discussing the fire with their own students there was a shared sense of pain, loss and the fear of reoccurrence. They had their students make simple drawings of their experiences and allowed them to share these openly. They noticed a kind of healing in the process that was more profound than in earlier discussions. These teachers decided to offer an afterschool workshop where they brought charcoal ash from the burned trees and had the students use the ash to draw scenes from their experience. The event was so powerful, students and parents asked for more workshops. Not feeling qualified in various art processes, the teachers requested help from some artist friends in the community. They mixed clay with ash and created pottery. They continued to use charcoal as a medium and introduced painting, created poems, short stories, and plays. The larger community became involved and experiences were created for adults as well. In the day-to-day classroom, the teachers allowed the students to have the emotional space they needed to process these experiences more deeply and eventually the impact of these experiences changed not only the way the teachers conceived of teaching, it changed their lives in profound ways. They were also asked to share their experience with other districts, with some of their students sharing their art-making and their stories. And ultimately, these two teachers did their Masters thesis on different aspects of this process and the transformative changes that took place.

This story, just like the raindrops falling into the lake, illustrates that emergence is not linear. What emerges goes in all directions at once, influencing everything and being influenced in return. From the planning of a simple sand painting activity and the introduction of the skills needed to create it, emerged the healing of a community and left an indelible mark on the teachers who allowed themselves to be agents of transformation. David created a space where teaching was not limited to the application of skills. Rather, students were invited to bring their own life-worlds into the process and to create a community where their stories could be honored and shared. In this process, the "curriculum" disappeared and something magical and unanticipated emerged. 


\title{
References
}

Buhner, S. (2004) The secret teachings of plants. The intelligence of the heart in the direct perception of nature. Rochester, Vermont: Bear \& Company.

\begin{abstract}
About the Authors
Sam Crowell is professor of education at California State University - San Bernardino and the founder and co-director of the MA in Holistic and Integrative Education and the Center for Holistic and Integrative Learning. As a holistic educator, he is an advocate of the artistry of teaching and an inspirited education. He started teaching in a small school in Appalachia, seeing teaching as a kind of engaged service to the world. His experiences there seeded his interest in educational alternatives, and an education that responds to real human needs and that transforms lives in the most profound ways. Together with Renata Nummela Caine and Geoffrey Caine he is the author of the books The ReEnchantment of Learning: A Manual for Teacher Renewal and Classroom Transformation (1997) and MindShifts: A Brain-Compatible Process for Professional Development and the Renewal of Education (1999)

David Reid-Marr is an adjunct professor in a Master's program at California State University-San Bernardino. He graduated from the Royal College of Art, London with a M.F.A. in painting and art history. He organized and participated in many site-specific installations in England and Wales before coming to the U.S. to study Zen Buddhism. This led to an interest in the relationship between religion and our perceptions, and to a series of large format drawings, found-object sculpture and performance work, which have been exhibited throughout the Western U.S. He and has an abiding interest in the theory and practice of alternative education.
\end{abstract}

(C) Copyright 2010. The authors, SAM CROWELL and DAVID REID-MARR assign to the University of Alberta and other educational and non-profit institutions a non-exclusive license to use this document for personal use and in courses of instruction provided that the article is used in full and this copyright statement is reproduced. The authors also grant a non-exclusive license to the University of Alberta to publish this document in full on the World Wide Web, and for the document to be published on mirrors on the World Wide Web. Any other usage is prohibited without the express permission of the authors. 